\title{
The microstructure and mechanical properties of Al-containing 9Cr ODS ferritic alloy
}

\author{
Guangming Zhang, ${ }^{\mathrm{a}, \mathrm{b}}$, Zhangjian Zhou ${ }^{\mathrm{a}, *}$, Kun $\mathrm{Mo}^{\mathrm{c}}$, Pinghuai Wang ${ }^{\mathrm{d}}$, Yinbin Miao ${ }^{\mathrm{b}}$, Shaofu $\mathrm{Li}^{\mathrm{a}}$, \\ Man Wang ${ }^{\mathrm{a}}$, Xiang Liu ${ }^{\mathrm{b}}$, Mengqiang Gong ${ }^{\mathrm{a}}$, Jonathan Almer ${ }^{\mathrm{e}}$, James F. Stubbins ${ }^{\mathrm{b}}$ \\ ${ }^{a}$ School of Materials Science and Engineering, University of Science and Technology, Beijing, Beijing 100083, China \\ ${ }^{b}$ Department of Nuclear, Plasma and Radiological Engineering, University of Illinois at Urbana-Champaign, IL 61801, \\ USA \\ ${ }^{c}$ Nuclear Engineering Division, Argonne National Laboratory, Argonne, IL 60439, USA \\ ${ }^{d}$ Fusion Reactor \& Materials Division, Southwestern Institute of Physics, Chengdu, Sichuan, 610041, China \\ ${ }^{e} X$-ray Science Division, Argonne National Laboratory, Argonne, IL 60439, USA
}

\begin{abstract}
In this study, a 9Cr oxide-dispersion strengthened (ODS) alloy with additional corrosion resistant element Al was fabricated by mechanical alloying (MA) and hot pressing (HP) to explore the impact of $\mathrm{Al}$ on the microstructure and mechanical property of a $9 \mathrm{Cr}$ ODS alloy. It is found that the $\mathrm{Al}$ completely dissolved into the Fe-Cr matrix after milling for $30 \mathrm{~h}$. The minor phases in the Al-containing 9Cr ODS ferritic alloy were investigated by a high-energy $\mathrm{X}$-ray, and were identified to be orthorhombic- $\mathrm{YAlO}_{3}$ (YAP), bcc- $\mathrm{Y}_{3} \mathrm{Al}_{5} \mathrm{O}_{12}$ (YAG), monoclinic- $\mathrm{Al}_{2} \mathrm{Y}_{4} \mathrm{O}_{9}$ (YAM), and hexagonal- $\mathrm{YAlO}_{3}$ (YAH). These phases were further confirmed by selected area diffraction pattern (SADP), energy dispersive spectroscopy (EDS), and high resolution transmission electron microscopy (HRTEM). In addition, their volume fractions were also calculated from the integrated intensities. According to the analysis of the particles and their formation sequences, the larger particles (greater than $100 \mathrm{~nm}$ ) are identified as mainly YAG and $\mathrm{Al}_{2} \mathrm{O}_{3}$ particles, while the particles with small size (less than $30 \mathrm{~nm}$ ) are likely primarily YAM, YAH, and YAP particles. The yielding strength (YS) and ultimate tensile strength (UTS) at RT are $563 \mathrm{MPa}$ and $744 \mathrm{MPa}$, respectively, while the YS and UTS at $700{ }^{\circ} \mathrm{C}$ are $245 \mathrm{MPa}$ and $276 \mathrm{MPa}$, respectively. Although the addition $\mathrm{Al}$ in ODS alloys decreases the strength at RT, the values at high temperature are similar to those obtained for 9Cr ODS alloys strengthened by fine Y-Ti-O particles.
\end{abstract}

Keywords: synchrotron, tensile deformation, nanoscale particles, microstructure

\section{Introduction}

The conflicts between the growing demand for energy and the goal of decreasing reliance on fossil fuels has motivated a worldwide interest in advanced nuclear energy $[1,2]$. Advanced nuclear reactors require new structural materials with excellent properties including high temperature

\footnotetext{
*Address: Laboratory of Special Ceramics and Powder Metallurgy, School of Material Science and Engineering, University of Science and Technology Beijing, Beijing 100083, P.R.China Tel: +86-10-62334951 Email: zhouzhj@mater.ustb.edu.cn
}

Preprint submitted to Journal of Alloys and Compounds

June 25, 2015 
strength, irradiation resistance, and corrosion resistance [1,3]. Ferritic/Martensitic oxide dispersion strengthened (ODS) alloys are one category of candidate structural materials for fuel cladding in next generation fission reactors $[4,5,6]$ due to their high creep strength $[7,8,9]$ and high irradiation resistance $[10,11,12]$. However, the poor corrosion resistance of F/M ODS alloys limits their development and applications in hostile environments such as the supercritical pressurized water reactor (SCPWR) [13, 14]. Recent study showed that the addition of $\mathrm{Al}$ in (12-19) $\mathrm{Cr}$ ferritic ODS alloys improved the corrosion resistance [15, 16, 17]. However, the $\alpha-\alpha^{\prime}$ phase separation in the high Cr content ODS alloy actually results in deteriorated mechanical properties $[18,19]$. Enenstam et al. [20] optimized the Fe-based alloy with a composition of $10 \mathrm{Cr}-4 \mathrm{Al}$ in a series of $10 \mathrm{Cr}$ alloys to balance the weldability, microstructural degradation, and corrosion resistance. So far, there is no report on the investigation of adding $\mathrm{Al}$ to a $9 \mathrm{Cr}$ ODS alloy.

The present study is an attempt to explore the possibility of fabrication of a 9Cr ODS alloy with the addition of $4.5 \mathrm{wt} \%$ corrosion resistance element Al. The microstructure and mechanical properties of the Al-containing 9Cr ODS ferritic alloy were investigated.

\section{Material and methods}

The starting materials with a nominal composition of Fe-9Cr-4.5Al-0.06C-1.5W-0.18Si-0.35 $\mathrm{Y}_{2} \mathrm{O}_{3}$ were mechanically alloyed (MA) using a planetary ball milling in a pure argon atmosphere at $300 \mathrm{rpm}$ with a ball-to-powder mass ratio of 5:1 for different intervals. The as-milled powders for both $15 \mathrm{~h}$ and $30 \mathrm{~h}$ of milling and the $30 \mathrm{~h}$ milling powders with subsequently annealing at $1200^{\circ} \mathrm{C}$ were investigated by scanning electron microscope (SEM, LEO-1450), X-ray diffraction (XRD, D/MAX-RB), and back scattered electron beam (BSEB). The as-milled powders after milling for $30 \mathrm{~h}$ were then consolidated by hot pressing (HP) using a graphite die under a pressure of $35 \mathrm{MPa}$ at $1200^{\circ} \mathrm{C}$ for $2 \mathrm{~h}$. The $\mathrm{BN}$ ceramic chips were put between the powders and the graphite die to avoid their reaction. The synchrotron irradiation of the as-HPed sample (9CrAl ODS alloy) was conducted at the 1-ID beamline at the Advanced Photon Source (APS) at Argonne National Laboratory (ANL). The diffraction analysis was performed by using a monochromatic $65 \mathrm{keV}$ synchrotron beam. The "Hydra" detector array was utilized to collect the diffraction information. Transmission electron microscopy (TEM) thin foil specimens were prepared by ion milling. The microstructure and chemical composition were characterized by TEM (JEM-2010) with an energy dispersive spectroscope (EDS). The nanoscale particles were investigated by high resolution transmission electron microscope (HRTEM). The as-HPed sample with a relative density of $98.6 \%$ was cut into tensile specimens with a gauge length of $5 \mathrm{~mm}$. Tensile tests were carried out at room temperature (RT) and $700^{\circ} \mathrm{C}$ with a strain rate of $10^{-3} s^{-1}$. The fracture surfaces of post-tensile specimens were also studied by SEM.

\section{Results and Discussion}

\subsection{Mechanical alloying}

The XRD patterns of the as-milled powders, after milling for $15 \mathrm{~h}$ and $30 \mathrm{~h}$ respectively, were shown in Figure 1. It can be seen that the Al peak still exists after milling for 15h, but disappears after $30 \mathrm{~h}$, which indicates that pure $\mathrm{Al}$ cannot completely dissolve into the $\mathrm{Fe}-\mathrm{Cr}$ matrix until $15 \mathrm{~h}$ of milling. In addition, the previous study showed the complete dissolution of $\mathrm{Y}_{2} \mathrm{O}_{3}$ in the MA process after milling for $30 \mathrm{~h} \mathrm{[21].} \mathrm{Therefore,} \mathrm{it} \mathrm{can} \mathrm{be} \mathrm{confirmed} \mathrm{that} \mathrm{it} \mathrm{is} \mathrm{sufficient} \mathrm{for}$ the starting powders to form a supersaturated solid solution by MA for $30 \mathrm{~h}$. Therefore only the 


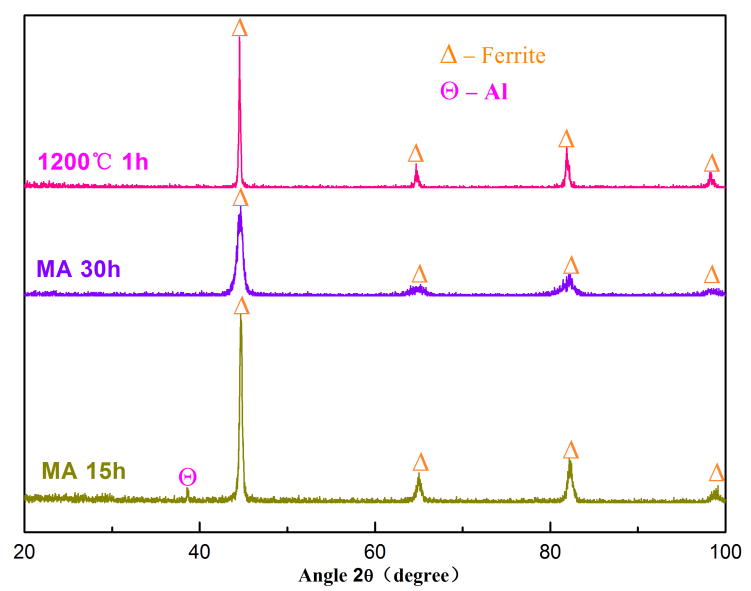

Figure 1: XRD patterns of the as-milled powders and the annealed powders.

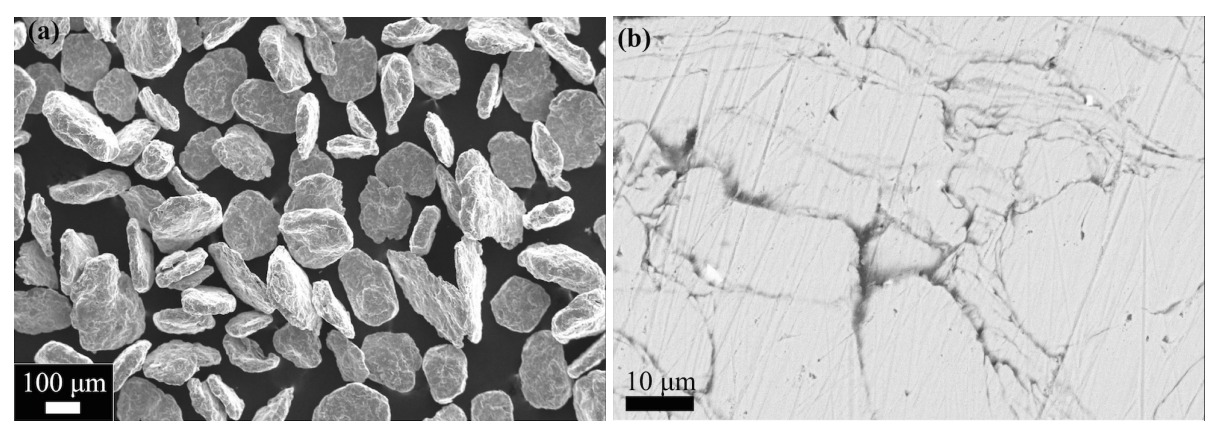

Figure 2: The as-milled powders after $30 \mathrm{~h}$ : (a) the morphology of powders by SEM; (b) the morphology of powder at cross-section by BSEB. 
as-milled powders after milling for $30 \mathrm{~h}$ were annealed at temperature of $1200{ }^{\circ} \mathrm{C}$ for $2 \mathrm{~h}$. The XRD pattern of the as-annealed powders was also shown in Figure 1, no new phase (obvious precipitate) was distinguished after annealing at $1200^{\circ} \mathrm{C}$. One should note that the minor phases were not identified due to the limited precision of XRD. Therefore, the results simply reveal that no major phase occurs after annealing at $1200{ }^{\circ} \mathrm{C}$. The minor phases will be discussed later by high energy X-ray and HRTEM investigations.

Figure 2 shows the morphology of the as-milled powders after $30 \mathrm{~h}$ of milling. The size of the powders shown in Figure 2 (a) ranges from 100 to $250 \mu \mathrm{m}$ with an average size of about $170 \mu \mathrm{m}$, Sakasegawa [22] concluded that larger powders (greater than $90 \mu \mathrm{m}$ ) have lower oxygen concentrations than smaller powders (less than $45 \mu \mathrm{m}$ ), which provides a great benefit to the creep resistance. The cross section morphology by BSEB confirms the complete dissolution of $\mathrm{Al}$ into the matrix after milling for 30h, which can be seen in Figure 2 (b).

\subsection{Microstructure characterization}

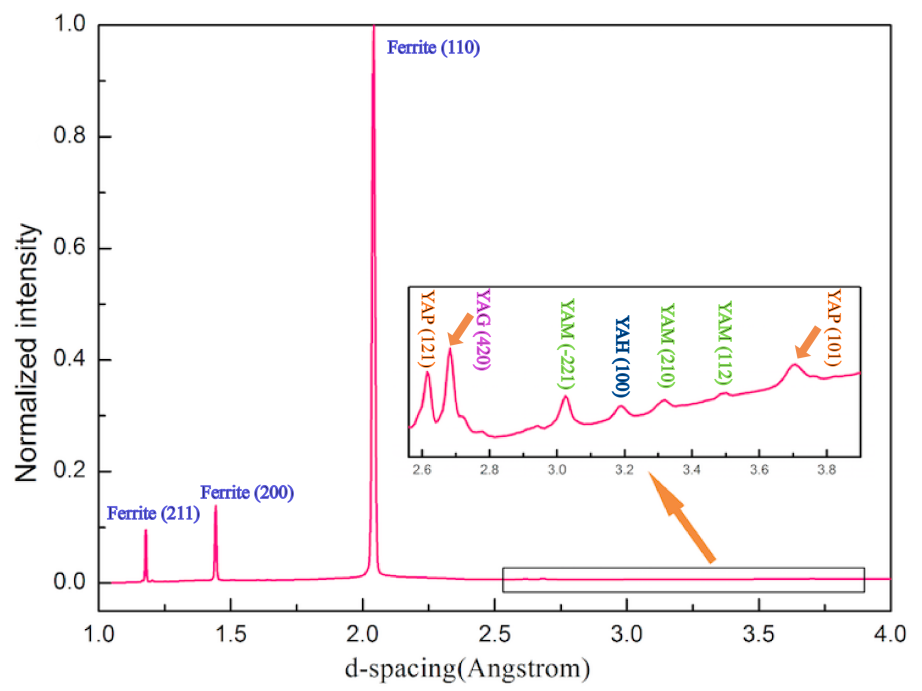

Figure 3: Synchrotron X-ray diffraction line profile of the 9CrAl ODS alloy; (Ferrite matrix phases, along with minor phases, orthorhombic $\mathrm{YAlO}_{3}$ (yttrium aluminum perovskite, YAP), bcc $\mathrm{Y}_{3} \mathrm{Al}_{5} \mathrm{O}_{12}$ (yttrium aluminum garnet, YAG), monoclinic $\mathrm{Al}_{2} \mathrm{Y}_{4} \mathrm{O}_{9}$ (yttrium aluminum monoclinic, YAM), and hexagonal $\mathrm{YAlO}_{3}$ (yttium aluminum hexagonal, YAH) were recognized.)

The 9CrAl ODS alloy was examined by high-energy X-ray technique. Figure 3 shows the $90^{\circ}$ integrated intensity as a function of the d-spacing. Multiple types of Y-Al-O are expected to precipitate in the $9 \mathrm{CrAl}$ ODS alloy during the process of consolidation [23, 24]. The large peaks were identified as ferrite, and four types of minor precipitates (Y-Al-O) were identified as: orthorhombic- $\mathrm{YAlO}_{3}$ (YAP), bcc- $\mathrm{Y}_{3} \mathrm{Al}_{5} \mathrm{O}_{12}$ (YAG), monoclinic- $\mathrm{Al}_{2} \mathrm{Y}_{4} \mathrm{O}_{9}$ (YAM), and hexagonal- $\mathrm{YAlO}_{3}$ (YAH). This result agrees with the ref. [25] that all these four types mixed Al-Y oxides were identified in INCONEL alloy MA6000. The integrated intensities were used to calculate the 
volume fractions of the corresponding phases based on Equation 1 [26].

$$
V_{i}=\frac{\frac{1}{n_{i}} \sum_{j=1}^{n_{i}} \frac{I_{i}^{j}}{R_{i}^{j}}}{\frac{1}{n_{a}} \sum_{j=1}^{n_{a}} \frac{I_{j}^{j}}{R_{a}^{j}}+\frac{1}{n_{p 1}} \sum_{j=1}^{n_{p 1}} \frac{I_{p 1}^{j}}{R_{p 1}^{j}}+\frac{1}{n_{p 2}} \sum_{j=1}^{n_{p 2}} \frac{I_{p 2}^{j}}{R_{p 2}^{j}}+\ldots}
$$

where, $V_{i}$ is the volume fraction of phase $i ; i$ represents Ferrite (subscript ${ }_{a}$ ) and various precipitates phases (subscripts ${ }_{p 1, p 2 \ldots}$ ); $I_{i}^{j}$ is the integrated intensity of the reflection of $j$ (for a specific $h k l$ ) for phase $i ; n_{i}$ is the number of the reflections analysed for a certain phase; and $R_{i}^{j}$ is the material scattering factor for a specific phase $(i)$ and reflection $(j)$, which has an expression in equation 2 as follows:

$$
R_{h k l}=\frac{1}{V^{2}}\left[|F|^{2} p\left(\frac{1+\cos ^{2} 2 \theta}{\sin ^{2} \theta \cos \theta}\right)\right] e^{-2 M}
$$

where $V$ is the volume of the unit cell; $F$ is the structure factor; $p$ is the multiplicity of the reflection; $\frac{1+\cos ^{2} 2 \theta}{\sin ^{2} \theta \cos \theta}$ is the Lorentz-polarization factor as a function of diffraction angle $\theta$; and $e^{-2 M}$ is the temperature factor. The volume fraction of each distinguishable precipitate phase was calculated and is listed in Table 1. These values were averaged from synchrotron wide-angle $\mathrm{X}$-ray scattering (WAXS) data collected at three different X-ray exposures. YAG has the largest volume fraction, up to $0.51 \%$, while the YAM has the smallest at $0.16 \%$. Hsiung et al. reported a primarily YAM distribution in the K3-ODS alloy, which was fabricated by hot extrusion at 1150 ${ }^{\circ} \mathrm{C}$ [27]. Zhang et al. reported that the nano-sized oxides in the MA956 consist mainly of $\mathrm{YAlO}_{3}$ in a perovskite structure (YAP) [28]. YAH was found to be the main species among oxides in the Ni-based ODS alloy MA6000 [25]. Dou et al. [29] confirmed that the hot extrusion temperature has a clear effect on both the particles size and number density, and reported a primarily YAH phase after $1050{ }^{\circ} \mathrm{C}$, and the occurrence of YAP after $1150{ }^{\circ} \mathrm{C}$ [30]. According to the internal oxidation and polymorphic transition reactions: $2 \mathrm{Y}_{2} \mathrm{O}_{3}+\mathrm{Al}_{2} \mathrm{O}_{3}(\gamma)=\mathrm{Y}_{4} \mathrm{Al}_{2} \mathrm{O}_{9}$ (YAM), $\mathrm{Al}_{2} \mathrm{O}_{3}$ $(\gamma)+Y_{4} \mathrm{Al}_{2} \mathrm{O}_{9}(\mathrm{YAM})=4 \mathrm{YAlO}_{3}(\mathrm{YAH}), \mathrm{YAH}$ transforms to YAP due to the affinity of oxygen for different solute atoms, and finally, $\mathrm{Al}_{2} \mathrm{O}_{3}(\gamma)+3 \mathrm{YAlO}_{3}$ (YAP) $=\mathrm{Y}_{3} \mathrm{Al}_{5} \mathrm{O}_{12}$ (YAG) [31, 32]. The volume fraction relationship for the four particle types (YAG $>$ YAP $>$ YAH $>$ YAM) may be explained by this formation sequence, which may due to the sintering process at $1200{ }^{\circ} \mathrm{C}$ and excess oxygen.

Table 1: Volume fractions of all the synchrotron-distinguishable precipitate phases in the 9CrAl ODS alloy.

\begin{tabular}{ccc}
\hline Formula & Structure & Volume Fraction \\
\hline \hline YAM & orthorhombic & $0.16 \pm 0.026 \%$ \\
YAH & hexagonal & $0.21 \pm 0.086 \%$ \\
YAP & pervoskite & $0.38 \pm 0.034 \%$ \\
YAG & garnet & $0.51 \pm 0.023 \%$ \\
\hline
\end{tabular}

The typical morphology of the 9 $\mathrm{CrAl}$ ODS alloy is shown in Figure 4. Figure 4 (a) shows a TEM bright field image of the $9 \mathrm{CrAl}$ alloy. The grain size is as large as several microns. The multiscale precipitates with sizes ranging from several to hundreds of nanometers distribute both in the grains and on the grain boundaries. Figure 4 (b) shows a view of the nanoscale particles in a grain of the $9 \mathrm{CrAl}$ ODS alloy. It can be seen that the smaller sized particles with a high number 


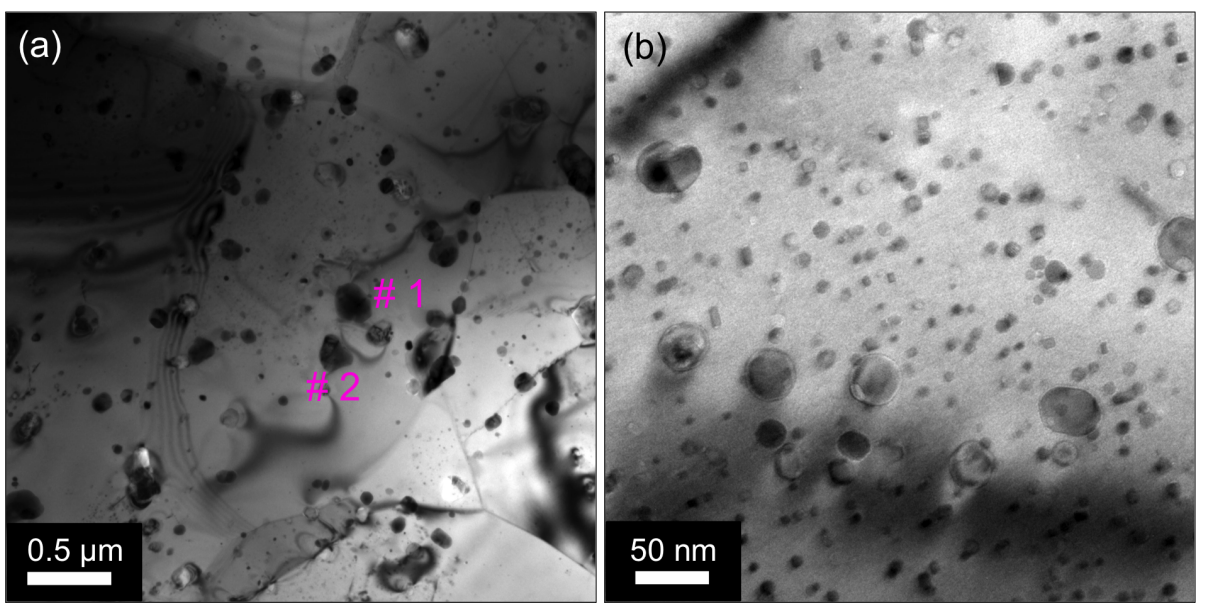

Figure 4: The bright field image of TEM for the 9CrAl ODS alloy in: (a) low magnification; (b) high magnification.

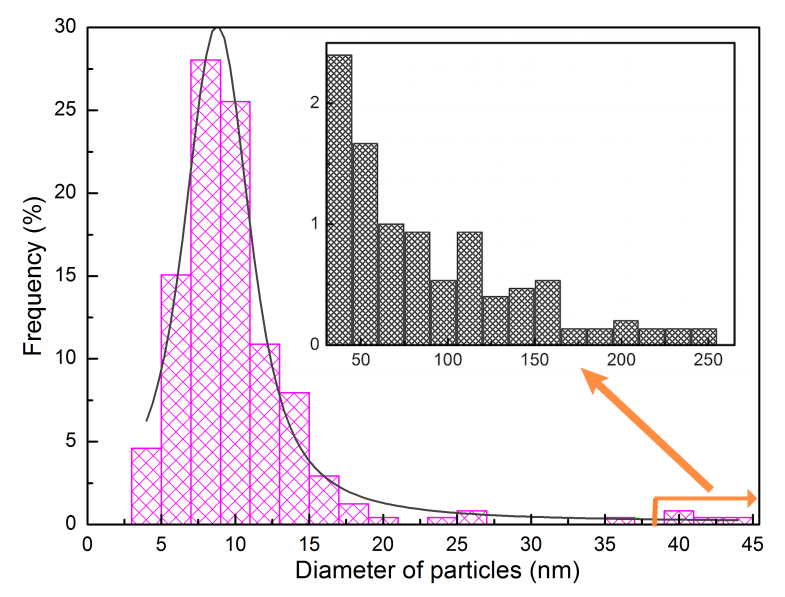

Figure 5: Size distribution of the oxide particles in the matrix of the 9CrAl ODS alloy. 
density distribute uniformly in the grain. The oxides particles size distribution was detected by the careful statistical image processing method using TEM pictures with different magnifications. Figure 5 shows the result, it can be seen that the effective diameter with the highest frequency is about $8 \mathrm{~nm}$. Most of the particles are smaller than $15 \mathrm{~nm}$. The large precipitates (greater than $100 \mathrm{~nm}$ ) seen in Figure 4 (a) are also included in this result, where their fraction is less than $1 \%$.
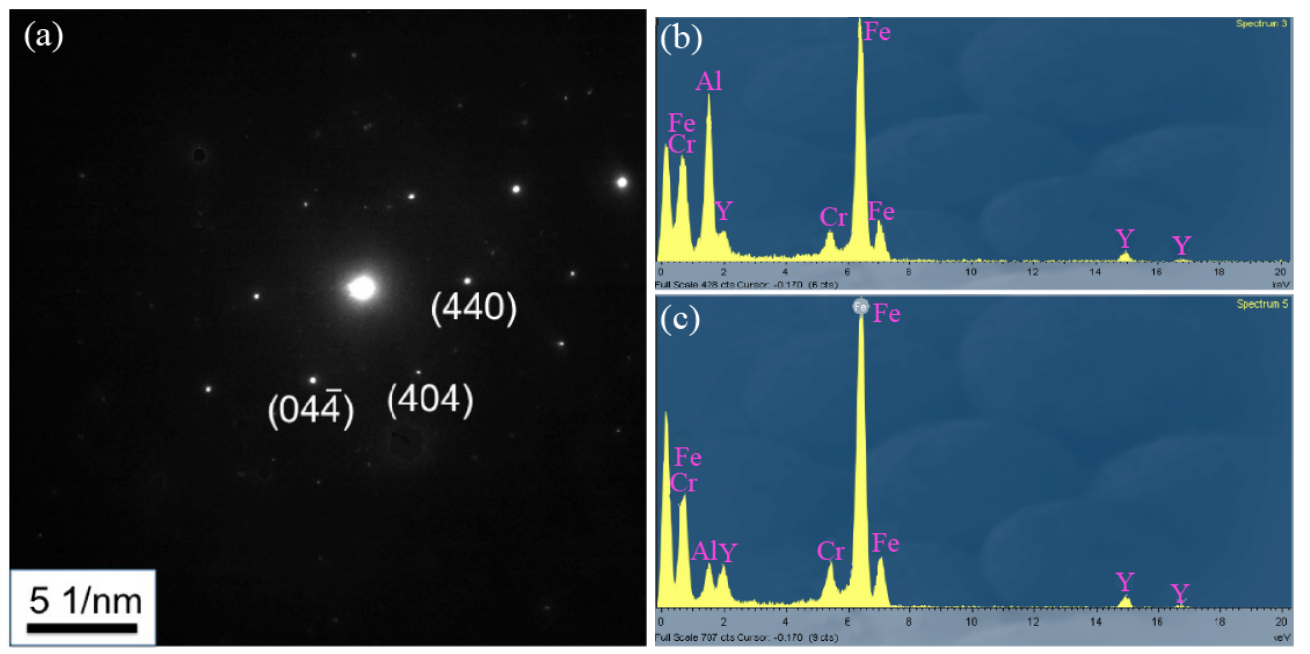

Figure 6: (a) selected area diffraction pattern of particle \# 1 in Figure 4, (b) the EDS of particle \# 1, (c) the EDS of particle \# 2 in Figure 4.

In order to identify the different precipitates in the 9CrAl ODS alloy, the precipitates were further investigated by EDS, selected area diffraction pattern (SADP), and HRTEM. The labeled particle (\# 1) in Figure 4 (a)) with a size of $240 \mathrm{~nm}$ was examined by SADP as shown in Figure 6 (a) and EDS as shown in Figure 6 (b). This particle was identified as $Y_{3} A l_{5} O_{12}$ (YAG) at the zone axis [111], while the atomic ratio of $\mathrm{Al} / \mathrm{Y} \approx 1.68$ for this particle confirms the $\mathrm{YAG}(\mathrm{Al} / \mathrm{Y}$ $\approx 1.67$ ). Another large precipitates (\# 2) in Figure 4 (a) was also examined by EDS, the so large atomic ratio of $\mathrm{Al} / \mathrm{Y}(\approx 37)$ indicates the very less-yttrium in this large particle, indicating the existence of $\mathrm{Al}_{2} \mathrm{O}_{3}$, which agrees with ref. [28]. However, the $\mathrm{Al}_{2} \mathrm{O}_{3}$ is not distinguishable in Figure 3, which may be ascribed to the very low volume fraction of $\mathrm{Al}_{2} \mathrm{O}_{3}$ or the nonuniform distribution of $\mathrm{Al}_{2} \mathrm{O}_{3}$ in the specimen.

Table 2: Measured and calculated inter-planar distances (d) and angles $(\alpha)$ of the nanoscale particle in Figure 7 and possible indexing.

\begin{tabular}{ccccccc}
\hline $\mathrm{d}(\AA), \alpha$ & $d_{1}$ & $d_{2}$ & $d_{3}$ & $\alpha_{12}\left(^{\circ}\right)$ & $\alpha_{23}\left(^{\circ}\right)$ & $\alpha_{13}\left(^{\circ}\right)$ \\
\hline \hline YAP & $\{1-2-1\} 2.61$ & $\{201\} 2.37$ & $\{122\} 1.97$ & 78.14 & 47.43 & 125.57 \\
Measured & 2.6 & 2.4 & 2.0 & 76.25 & 48.86 & 125.11 \\
YAM & $\{13-1\} 3.14$ & $\{202\} 3.51$ & $\{1-3-1\} 3.14$ & 63.44 & 63.43 & 126.87 \\
Measured & 3.2 & 3.4 & 3.2 & 63.48 & 62.94 & 126.42 \\
\hline
\end{tabular}

The nanoscale particles in Figure 4 (b) were investigated by HRTEM. Figure 7 (a) and (b) show a YAP particle with a diameter of about $36 \mathrm{~nm}$, and Figure 7 (c) and (d) show a YAM 


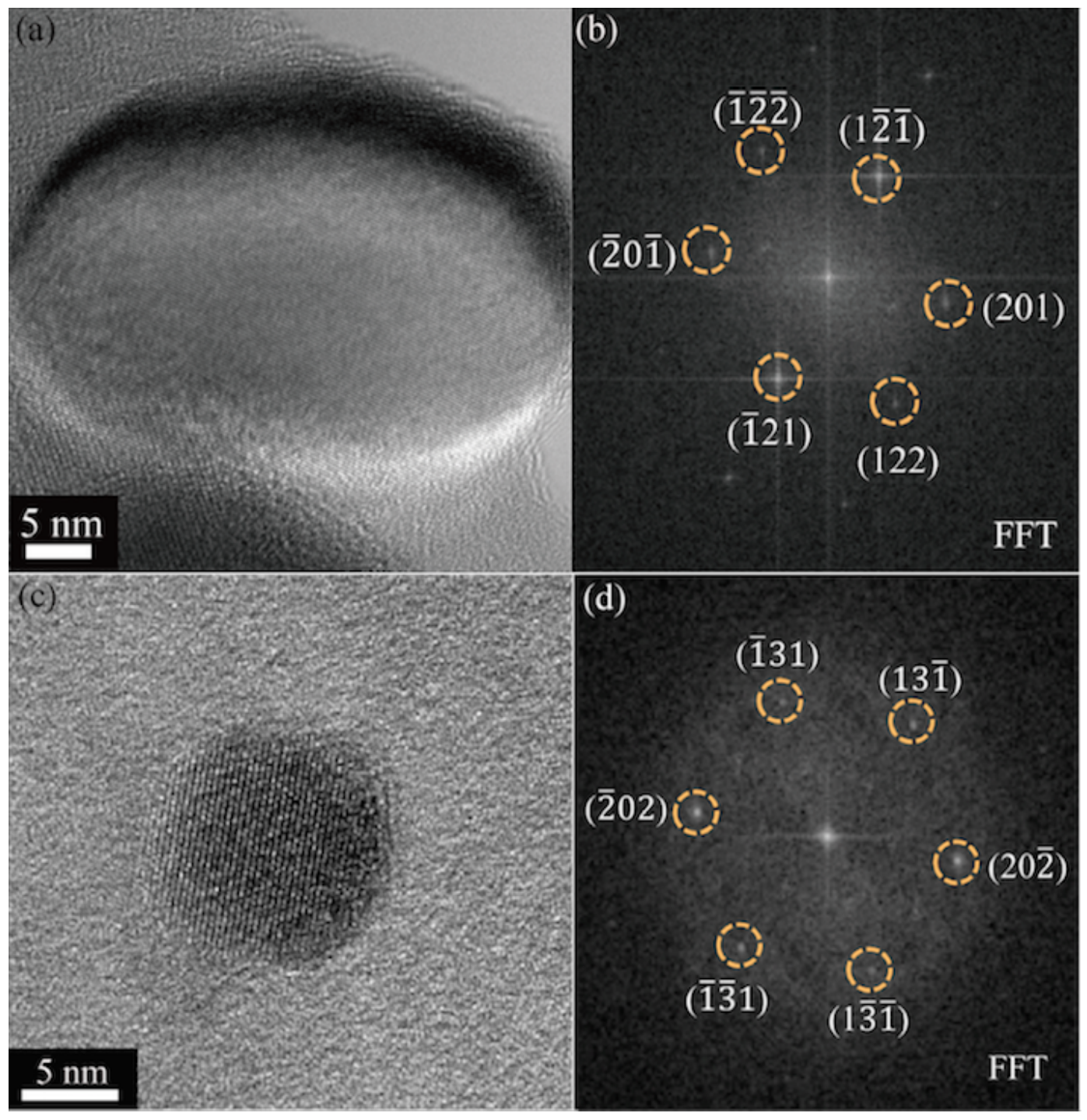

Figure 7: (a) HRTEM micrograph of an YAP particle with diameter of about $36 \mathrm{~nm}$, (b) FFT diagram of the micrograph in (a); (c) HRTEM micrograph of an YAM particle with diameter of about $10 \mathrm{~nm}$, (d) FFT diagram of the micrograph in (c). 
particle with a diameter of about $10 \mathrm{~nm}$. Table 2 lists the measured inter-planar spacing and angles of these particles. The measured values for these particles are consistent with those of

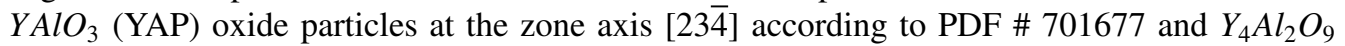
(YAM) at the zone axis [101] according to PDF \# 830935, respectively. However, no YAH particle was distinguished by HRTEM, the absence of YAH cannot be concluded due to the YAH peaks in Figure 3. According to the above analysis for particles and their formation sequences, the larger particles (greater than $100 \mathrm{~nm}$ ) are assumed to be mainly YAG and $\mathrm{Al}_{2} \mathrm{O}_{3}$, while the smaller sized particles (less than $30 \mathrm{~nm}$ ) may be primarily YAM, YAH, and YAP particles.

\subsection{Mechanical properties}

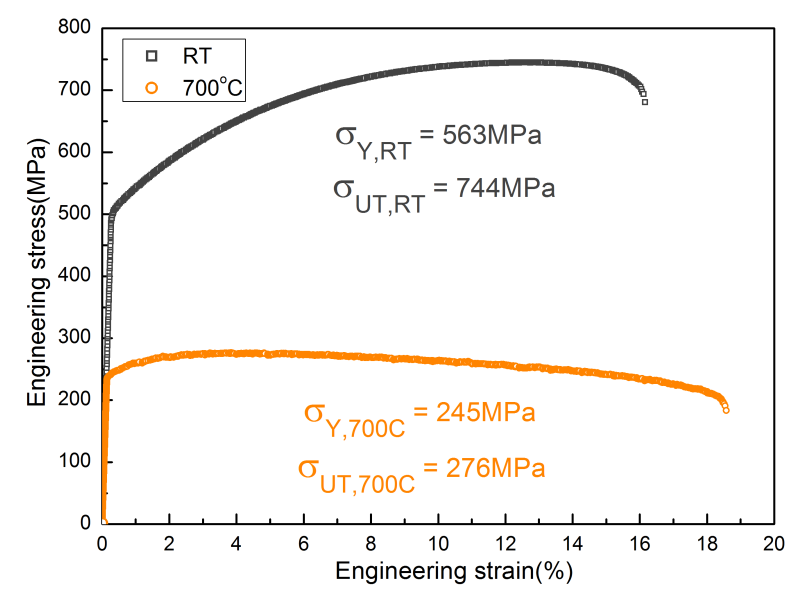

Figure 8: Strian-stress curves of the $9 \mathrm{CrAl}$ ODS alloy at RT and $700{ }^{\circ} \mathrm{C}$.

Figure 8 shows the tensile properties of the $9 \mathrm{CrAl}$ ODS alloy at RT and $700{ }^{\circ} \mathrm{C}$. The yield strength (YS) and ultimate tensile strength (UTS) at RT are $563 \mathrm{MPa}$ and $744 \mathrm{MPa}$, respectively, while the YS and UTS at $700{ }^{\circ} \mathrm{C}$ drop to $245 \mathrm{MPa}$ and $276 \mathrm{MPa}$, respectively. The YS and UTS at RT are lower than those of 9Cr ODS alloys, while the values for the 9CrAl ODS alloy at $700{ }^{\circ} \mathrm{C}$ are similar to those for $9 \mathrm{Cr}$ ODS alloys [33, 34, 35, 36] and much higher than those for non-ODS alloys such as CLAM and Eurofer 97 [37, 38]. As is well known, Al can influence the ductility and strength of the ODS alloys. The strength decreases with the increasing of the $\mathrm{Al}$ fraction in the level of lower than $0.1 \mathrm{wt} \%$ at $700{ }^{\circ} \mathrm{C}$ [23], the UTS of $14 \mathrm{Cr}-\mathrm{Al}$ ODS alloy is much lower than that of $14 \mathrm{Cr}$-Ti ODS alloy at both RT and $700{ }^{\circ} \mathrm{C}$ [39]. From these results, both the elongation and strength of the $9 \mathrm{CrAl}$ ODS alloy at $700{ }^{\circ} \mathrm{C}$ are acceptable compared to $9 \mathrm{Cr}$ ODS alloys. Figure 9 shows the fracture surface of specimens tested at RT and $700{ }^{\circ} \mathrm{C}$. It can be seen that the fracture surface of the specimen tested at RT contains a cleavage type feature, which is surrounded by a dimple type feature. In spite that the fracture surface at $700{ }^{\circ} \mathrm{C}$ is covered by a thin oxidation layer, the large dimple can still be seen clearly, which reveals the good ductility of the $9 \mathrm{CrAl}$ ODS alloy at $700{ }^{\circ} \mathrm{C}$. 


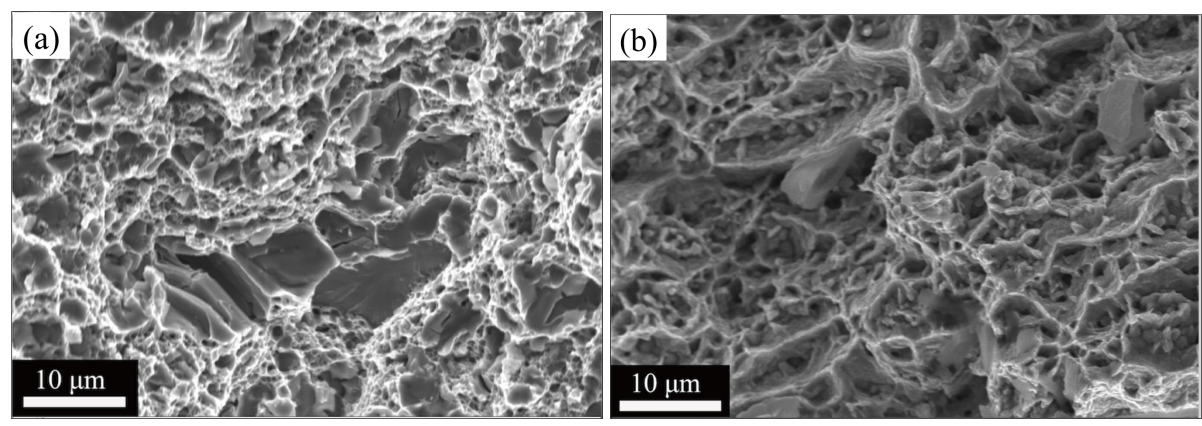

Figure 9: SEM images of fracture surfaces of the specimens strained at different temperatures: (a) RT; and (b) $700{ }^{\circ} \mathrm{C}$.

\subsection{Possible mechanism}

The thermal stability of multiple types Y-Al-O in INCONEL alloy MA6000 has been investigated at high temperature up to $850{ }^{\circ} \mathrm{C}$ [40]. In this work, they reported that there are no detectable coarsening of particles and no energy for transformation of particles at this temperature. Therefore, the particles should be very stable in the process of tensile test at $700{ }^{\circ} \mathrm{C}$. The excellent mechanical properties of ODS alloys at high temperature can be ascribed to the dispersed nano sized particles (Orowan strengthening and the cutting mechanism) [41]. The strengthening effect of the Orowan mechanism depends on the particle size and number density while the cutting mechanism is related to the coherency between the particles and the matrix. The smaller sized particles (YAM, YAH, and YAP) have been verified to tend to be coherent or semi-coherent with the matrix $[27,30]$, which may yield good strengthening phases. In the process of tensile deformation at $700{ }^{\circ} \mathrm{C}$, the nanoscale particles in the grains impede the movement of dislocations and the large particles on the grain boundaries hinder the sliding of grain boundaries, as shown in Figure 10. In addition, the 9CrAl ODS alloy has a larger grain size compared with 9Cr ODS alloys without Al addition, the large grain sized materials may be stronger at high temperature due to less tendency for grain boundary sliding [42]. Therefore, although Al softened the matrix of 9CrAl ODS alloy, the $9 \mathrm{CrAl}$ ODS alloy still possess good mechanical property at $700{ }^{\circ} \mathrm{C}$.

\section{Conclusion}

The 9CrAl ODS alloy was fabricated by MA and HP. It is found that the Al completely dissolved in the $\mathrm{Fe}-\mathrm{Cr}$ matrix after milling for $30 \mathrm{~h}$. The precipitates in the as-HPed sample were identified as orthorhombic- $\mathrm{YAlO}_{3}$ (YAP), bcc- $\mathrm{Y}_{3} \mathrm{Al}_{5} \mathrm{O}_{12}$ (YAG), monoclinic- $\mathrm{Al}_{2} \mathrm{Y}_{4} \mathrm{O}_{9}$ (YAM), and hexagonal- $\mathrm{YAlO}_{3}(\mathrm{YAH})$ by high-energy $\mathrm{X}$-ray techniques. In addition, the volume fractions of the four types of precipitates were calculated from the integrated intensities. The microstructure was investigated by TEM and HRTEM. The size distribution of particles ranges from several to hundreds of nanometers, and most of the particles are smaller than $15 \mathrm{~nm}$. The large particles (greater than $100 \mathrm{~nm}$ ) are concluded to be YAG and $\mathrm{Al}_{2} \mathrm{O}_{3}$ by SADP and EDS, while the small size particles primarily belong to YAM, YAH, and YAP. The YS and UTS at RT are $563 \mathrm{MPa}$ and $744 \mathrm{MPa}$, respectively, while the YS and UTS at $700{ }^{\circ} \mathrm{C}$ remain at $245 \mathrm{MPa}$ and $276 \mathrm{MPa}$, respectively. The elongation increases from $16 \%$ to $19 \%$ with the temperature increasing from RT to $700{ }^{\circ} \mathrm{C}$. 


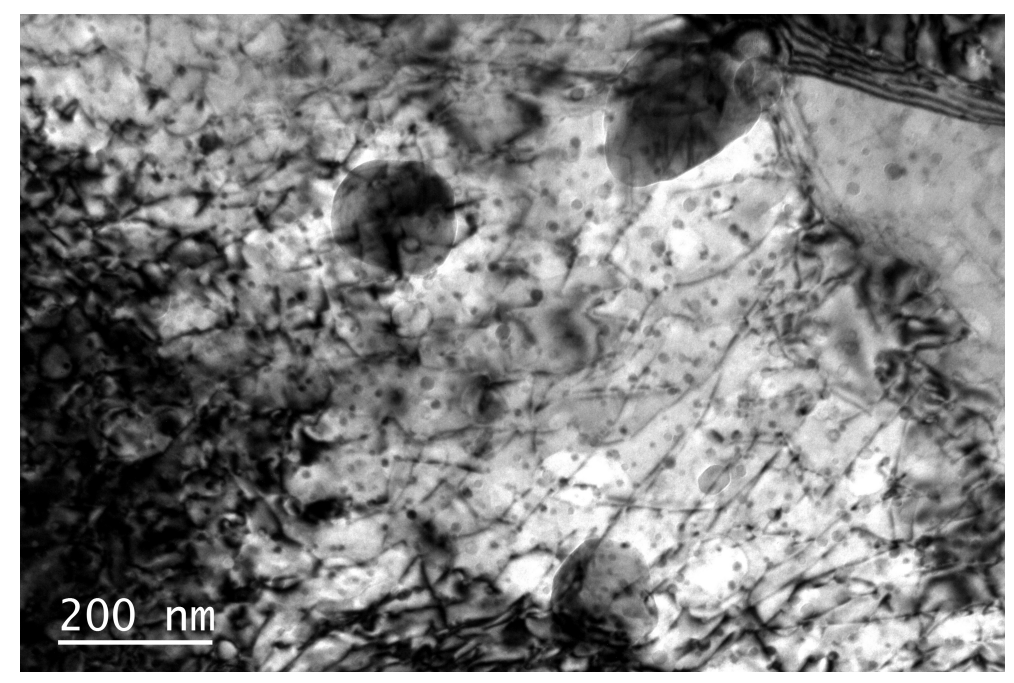

Figure 10: TEM bight field image of the gauge areas of the post strained specimens at $700^{\circ} \mathrm{C}$.

\section{Acknowledgement}

This work was supported by the National Magnetic Confinement Fusion Program of China under Grant No. 2015GB121006 and the International S\&T Cooperation Program of China (No.2013DFG62090). The authors also would like to express their thanks for Argonne National Laboratory's work supported by U.S. DOE under Contract No. DE-AC02-06CH11357.

\section{References}

[1] G. Locatelli, M. Mancini, N. Todeschini, Generation IV nuclear reactors: Current status and future prospects, Energy Policy 61 (2013) 1503-1520.

[2] G. Odette, M. Alinger, B. Wirth, Recent developments in irradiation-resistant steels, Annu. Rev. Mater. Res. 38 (2008) 471-503.

[3] P. Yvon, F. Carré, Structural materials challenges for advanced reactor systems, Journal of Nuclear Materials 385 (2) (2009) 217-222.

[4] R. Klueh, J. Shingledecker, R. Swindeman, D. Hoelzer, Oxide dispersion-strengthened steels: A comparison of some commercial and experimental alloys, Journal of Nuclear Materials 341 (2) (2005) 103-114.

[5] R. Lindau, A. Möslang, M. Schirra, P. Schlossmacher, M. Klimenkov, Mechanical and microstructural properties of a hipped RAFM ODS-steel, Journal of Nuclear Materials 307 (2002) 769-772.

[6] S. Noh, R. Kasada, A. Kimura, S. H. C. Park, S. Hirano, Microstructure and mechanical properties of friction stir processed ODS ferritic steels, Journal of Nuclear Materials 417 (1) (2011) 245-248.

[7] R. Lindau, A. Möslang, M. Rieth, M. Klimiankou, E. Materna-Morris, A. Alamo, A.-A. Tavassoli, C. Cayron, A.-M. Lancha, P. Fernandez, et al., Present development status of EUROFER and ODS-EUROFER for application in blanket concepts, Fusion Engineering and design 75 (2005) 989-996.

[8] S. Ohtsuka, S. Ukai, H. Sakasegawa, M. Fujiwara, T. Kaito, T. Narita, Nano-mesoscopic structural characterization of 9Cr-ODS martensitic steel for improving creep strength, Journal of Nuclear Materials 367 (2007) 160-165.

[9] H. Sakasegawa, S. Ohtsuka, S. Ukai, H. Tanigawa, M. Fujiwara, H. Ogiwara, A. Kohyama, Microstructural evolution during creep of 9Cr-ODS steels, Fusion engineering and design 81 (8) (2006) 1013-1018.

[10] T. Allen, J. Gan, J. Cole, S. Ukai, S. Shutthanandan, S. Thevuthasan, The stability of 9Cr-ODS oxide particles under heavy-ion irradiation, Nuclear science and engineering 151 (3) (2005) 305-312.

[11] A. Certain, K. G. Field, T. R. Allen, M. Miller, J. Bentley, J. Busby, Response of nanoclusters in a 9Cr ODS steel to $1 \mathrm{dpa}, 525$ C proton irradiation, Journal of Nuclear Materials 407 (1) (2010) 2-9. 
[12] S. Ukai, M. Fujiwara, Perspective of ODS alloys application in nuclear environments, Journal of Nuclear Materials 307 (2002) 749-757.

[13] H. S. Cho, A. Kimura, S. Ukai, M. Fujiwara, Corrosion properties of oxide dispersion strengthened steels in super-critical water environment, Journal of Nuclear Materials 329 (2004) 387-391.

[14] A. Alamo, V. Lambard, X. Averty, M. Mathon, Assessment of ODS-14\% Cr ferritic alloy for high temperature applications, Journal of Nuclear Materials 329 (2004) 333-337.

[15] A. Kimura, R. Kasada, N. Iwata, H. Kishimoto, C. Zhang, J. Isselin, P. Dou, J. Lee, N. Muthukumar, T. Okuda, et al., Development of Al added high-Cr ODS steels for fuel cladding of next generation nuclear systems, Journal of Nuclear Materials 417 (1) (2011) 176-179.

[16] H. Je, A. Kimura, Stress corrosion cracking susceptibility of oxide dispersion strengthened ferritic steel in supercritical pressurized water dissolved with different hydrogen and oxygen contents, Corrosion Science 78 (2014) 193-199.

[17] H. S. Cho, H. Ohkubo, N. Iwata, A. Kimura, S. Ukai, M. Fujiwara, Improvement of compatibility of advanced ferritic steels with super critical pressurized water toward a higher thermally efficient water-cooled blanket system, Fusion engineering and design 81 (8) (2006) 1071-1076.

[18] C. Capdevila, M. K. Miller, K. F. Russell, J. Chao, J. L. González-Carrasco, Phase separation in PM 2000® Fe-base ODS alloy: Experimental study at the atomic level, Materials Science and Engineering: A 490 (1) (2008) 277-288.

[19] C. Capdevila, M. K. Miller, K. F. Russell, Aluminum partitioning during phase separation in $\mathrm{Fe}-20 \% \mathrm{Cr}-6 \% \mathrm{Al}$ ODS alloy, Journal of Materials Science 43 (11) (2008) 3889-3893.

[20] J. Ejenstam, M. Thuvander, P. Olsson, F. Rave, P. Szakalos, Microstructural stability of Fe-Cr-Al alloys at 450-550 C, Journal of Nuclear Materials 457 (2015) 291-297.

[21] M. Wang, Z. Zhou, H. Sun, H. Hu, S. Li, Microstructural observation and tensile properties of ODS-304 austenitic steel, Materials Science and Engineering: A 559 (2013) 287-292.

[22] H. Sakasegawa, S. Ohtsuka, S. Ukai, H. Tanigawa, M. Fujiwara, H. Ogiwara, A. Kohyama, Particle size effects in mechanically alloyed 9Cr ODS steel powder, Journal of nuclear materials 367 (2007) 185-190.

[23] S. Ohtsuka, T. Kaito, M. Inoue, T. Asayama, S. Kim, S. Ukai, T. Narita, H. Sakasegawa, Effects of aluminum on high-temperature strength of 9Cr-ODS steel, Journal of Nuclear Materials 386 (2009) 479-482.

[24] Y. Xia, X. Wang, Z. Zhuang, Q. Sun, T. Zhang, Q. Fang, T. Hao, C. Liu, Microstructure and oxidation properties of $16 \mathrm{Cr}-5 \mathrm{Al}-\mathrm{ODS}$ steel prepared by sol-gel and spark plasma sintering methods, Journal of Nuclear Materials 432 (1) (2013) 198-204.

[25] G. Schaffer, M. Loretto, R. Smallman, J. Brooks, The nature of the dispersoids in INCONEL alloy M A6000, Journal of materials science 24 (9) (1989) 3261-3266.

[26] A. K. De, D. C. Murdock, M. C. Mataya, J. G. Speer, D. K. Matlock, Quantitative measurement of deformation-induced martensite in 304 stainless steel by X-ray diffraction, Scripta Materialia 50 (12) (2004) $1445-1449$.

[27] L. Hsiung, M. Fluss, S. Tumey, J. Kuntz, B. El-Dasher, M. Wall, B. Choi, A. Kimura, F. Willaime, Y. Serruys, HRTEM study of oxide nanoparticles in K3-ODS ferritic steel developed for radiation tolerance, Journal of Nuclear Materials 409 (2) (2011) 72-79.

[28] C. Zhang, A. Kimura, R. Kasada, J. Jang, H. Kishimoto, Y. Yang, Characterization of the oxide particles in Al-added high-Cr ODS ferritic steels, Journal of Nuclear Materials 417 (1) (2011) 221-224.

[29] P. Dou, A. Kimura, T. Okuda, M. Inoue, S. Ukai, S. Ohnuki, T. Fujisawa, F. Abe, Effects of extrusion temperature on the nano-mesoscopic structure and mechanical properties of an Al-alloyed high-Cr ODS ferritic steel, Journal of Nuclear Materials 417 (1) (2011) 166-170.

[30] P. Dou, A. Kimura, T. Okuda, M. Inoue, S. Ukai, S. Ohnuki, T. Fujisawa, F. Abe, Polymorphic and coherency transition of Y-Al complex oxide particles with extrusion temperature in an Al-alloyed high-Cr oxide dispersion strengthened ferritic steel, Acta Materialia 59 (3) (2011) 992-1002.

[31] X. Li, J.-G. Li, Z. Xiu, D. Huo, X. Sun, Transparent Nd: YAG Ceramics Fabricated Using Nanosized $\gamma$-Alumina and Yttria Powders, Journal of the American Ceramic Society 92 (1) (2009) 241-244.

[32] W. Si, C. Ding, S. Ding, Synthesis and characterization of YAG nanoparticles by ultrasound-assisted and ultrasound-microwave-assisted alkoxide hydrolysis precipitation methods, Journal of Nanomaterials 2014.

[33] V. De Castro, T. Leguey, A. Munoz, M. Monge, P. Fernández, A. Lancha, R. Pareja, Mechanical and microstructural behaviour of Y 2 O 3 ODS EUROFER 97, Journal of Nuclear Materials 367 (2007) 196-201.

[34] R. Schaeublin, T. Leguey, P. Spätig, N. Baluc, M. Victoria, Microstructure and mechanical properties of two ODS ferritic/martensitic steels, Journal of nuclear materials 307 (2002) 778-782.

[35] G. Zhang, Z. Zhou, M. Wang, S. Li, L. Zou, L. Zhang, Tensile and Charpy impact properties of an ODS ferritic/martensitic steel 9Cr-1.8 W-0.5 Ti-0.35 Y 2 O 3, Fusion Engineering and Design 89 (4) (2014) $280-283$.

[36] T. Muroga, T. Nagasaka, Y. Li, H. Abe, S. Ukai, A. Kimura, T. Okuda, Fabrication and characterization of reference 9Cr and 12Cr-ODS low activation ferritic/martensitic steels, Fusion Engineering and Design 89 (7) (2014) $1717-1722$. 
[37] Y. Li, Q. Huang, Y. Wu, T. Nagasaka, T. Muroga, Mechanical properties and microstructures of China low activation martensitic steel compared with JLF-1, Journal of Nuclear Materials 367 (2007) 117-121.

[38] B. Van der Schaaf, F. Tavassoli, C. Fazio, E. Rigal, E. Diegele, R. Lindau, G. LeMarois, The development of EUROFER reduced activation steel, Fusion Engineering and Design 69 (1) (2003) 197-203.

[39] M. Gong, Z. Zhou, H. Hu, G. Zhang, S. Li, M. Wang, Effects of aluminum on microstructure and mechanical behavior of 14Cr-ODS steels, Journal of Nuclear Materials .

[40] G. Schaffer, M. Loretto, R. Smallman, J. Brooks, The stability of the oxide dispersion in INCONEL alloy MA6000, Acta Metallurgica 37 (9) (1989) 2551-2558.

[41] R. Herrick, J. Weertman, R. Petkovic-Luton, M. Luton, Dislocation/particle interactions in an oxide dispersion strengthened alloy, Scripta metallurgica 22 (12) (1988) 1879-1884.

[42] F. C. Campbell, Elements of metallurgy and engineering alloys, ASM International, 2008. 